\title{
Research of modes and work of a combined unit for subsoil application of protective- stimulating liquids in spaces between rows of gardens and vineyards
}

\author{
Svetlana M. Borisova ${ }^{1}$, Sergey K. Papusha ${ }^{1, *}$, Vladimir K. Papusha ${ }^{1}$, Nikolay A. Nikitenko ${ }^{1}$ \\ ${ }^{1}$ Federal State Budgetary Educational Institution of Higher Education "Kuban State Agrarian \\ University named after I.T. Trubilin”, Krasnodar, Russia
}

\begin{abstract}
The combined unit is used for tillage and subsurface belt application of protective and stimulating liquids and microorganisms into the soil. New technology offers for the task to use pneumatic slotted sprayers with jet-forming device that is linked with a compressor that delivers air to transform the operation fluid from the tank in the aerial-droplet jet processing lower layers of the soil simultaneously with cultivation. Protective shields save the sprayer from deformation and breakage. To obtain the required range of the jet, the angle of inclination of the sprayer is adjusted. The supply line of operation fluid has an equalizing capacity to change the flow rate of the operation fluid. The basis of the development of sprayers was the task of development of a planeparallel jet capable of spreading to a distance to $2 \mathrm{~m}$ with an adjustable width of a grip $\mathrm{m} / \mathrm{s}$. there were conducted the researches of performance (charge) of pneumatic slotted sprayer depending on air pressure given to in slotted nozzles of the sprayer.
\end{abstract}

The combined unit refers to agricultural machinery and can be used for tillage, subsoil fertilizing, application of liquid fertilizers, protective and stimulating liquids and microorganisms in the spaces between rows of orchards and vineyards.

The offered equipment for integrated solutions for this task, previously used for tillage, is bulky and complex. This requires a somewhat new approach to the development of combined units and their research.

The purpose of researches: to determine the optimal design and technological scheme and operating parameters for resource-saving technology of combined tillage by loosening with the introduction of protective and stimulating agents into subsoil layer through the spraying device.

Given that a significant amount of organic and mineral fertilizers is needed to restore soil fertility, it is necessary to pay special attention to the development and research of

\footnotetext{
*Corresponding author: sergey_belousov_87@mail.ru
} 
various devices and devices for subsoil fertilization. Along with the above-mentioned fertilizers, various biological products, plant growth stimulants, microorganisms are used for the introduction into soil.

It is most effective to make them in small doses, evenly distributing them in soil and, preferably in liquid form, for more effective use.

In this regard, we recommend an ultra-low volume method of their application by pneumatic slotted sprayers designed in Kuban State Agrarian University in the department "Processes and machines in agribusiness" [1,3].

To obtain a technical result and improving the quality of tillage by loosening, a new technology of introduction of working fluid by belt way to a predetermined depth through the use of pneumatic slotted sprays with jet-forming device, filling tube and protective flaps located on the sides of jet-forming device, which is connected with the tank for working liquid and with the compressor from a filling tube giving air.

Fluid is introduced under the soil uniformly with air jet and is distributed over the width of the claw, with small doses (ultra small volume) in the area under soil which is lifted and loosened by tillage working body of the cultivator-type claw with various size parameters (Fig. 1).

The combined tillage tool has a frame 1, working bodies 2 on racks 3 and filling tubes 4 with sprayers 5, tank 6 for the operation solution. Each working body 2 on the stand 3 is mounted a bracket 7 with the dispenser 5 in the form of a pneumatic atomizer with a slotted jet-forming device 8 , filling tube 9 and the protective shields 10 are positioned on the sides of jet-forming device 8 through the filling tube 9 is linked with the tank 6 for the operation solution and with the compressor 11 giving air. The compressor 11 is connected to the receiver 12 , pressure regulator 13 , air channel 14 . Protective flaps 10 protect the atomizer 5 , pneumatic and hydraulic drives 15,16 from deformation and breaking. With the help of bracket 7 , the angle of inclination of the sprayer is adjusted to obtain the necessary range of the air-droplet jet and the quality of distribution of the operation fluid. Tank 6 for the operation solution has a supply line 17 of the operation solution with an equalizing capacity 18 and a bypass valve 19 .

Combined soil cultivating units operate in the following way: When moving the unit, 2 claws loosen soil, where by gravity the operation fluid is fed from the tank 6 via the supply lines 17 in the surge vessel 18 and bypass valve 19 is fed into the filling tube 9 of the dispenser 5 , through which is fed on air jet from the nozzle of the jet-forming device 8 to which air is supplied from compressor 11 through the receiver 12 and pressure regulator 13 via the air channel 14.
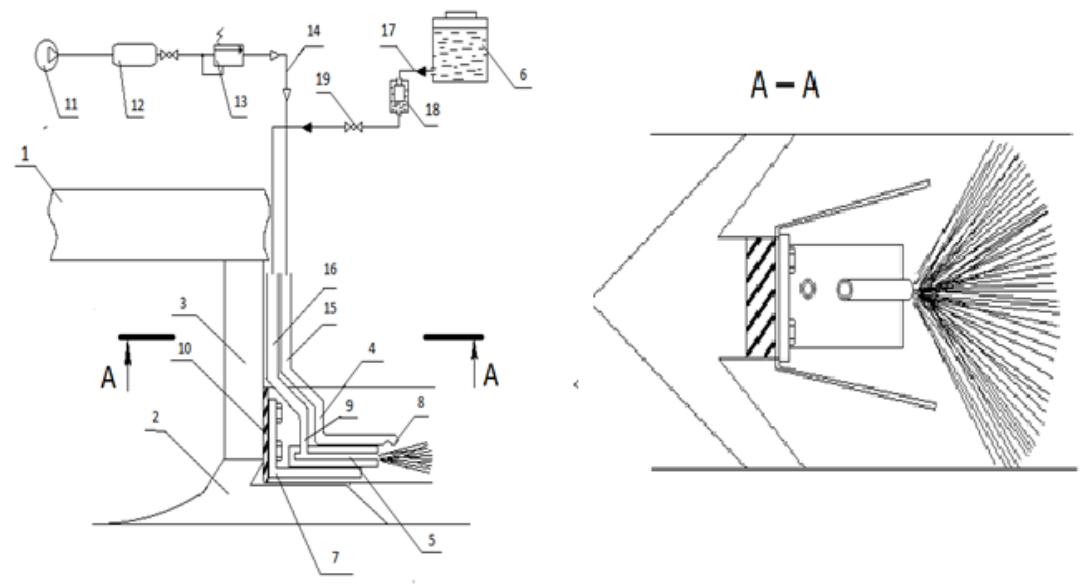

Fig. 1. Combined tillage tool with pneumatic slotted sprayers. 
An air-droplet jet is formed with the possibility of changing the angle of inclination, which spreads under soil cut and is raised by the cultivator's claw and is evenly distributed over the width of the inner furrow at the depth of the corresponding depth of tillage. Pneuma 15 and pneumatic hydraulic actuators 16 leading to the sprayer, fastened on the frame of the claw to the rear side are protected by protective pads 10 from damages and soil clogging.

The use of a combined tillage tool of this type will allow to treat the lower soil layers with liquid preparations, improve the quality of distribution of operation fluid under the soil layer at a given depth, reduce the consumption of operation fluid, increase the yield of a cultivated crop.

The basis under the development of sprayers is the creation of a plane-parallel jet capable of spreading at a distance of up to $2 \mathrm{~m}$ with the possibility of adjusting the width of grip.

Given that the pneumatic jet is formed by the sprayer set for cultivating a working body, namely, behind cultivator claws, you need to adjust or have a range of flat jet pneumatic sprayers.

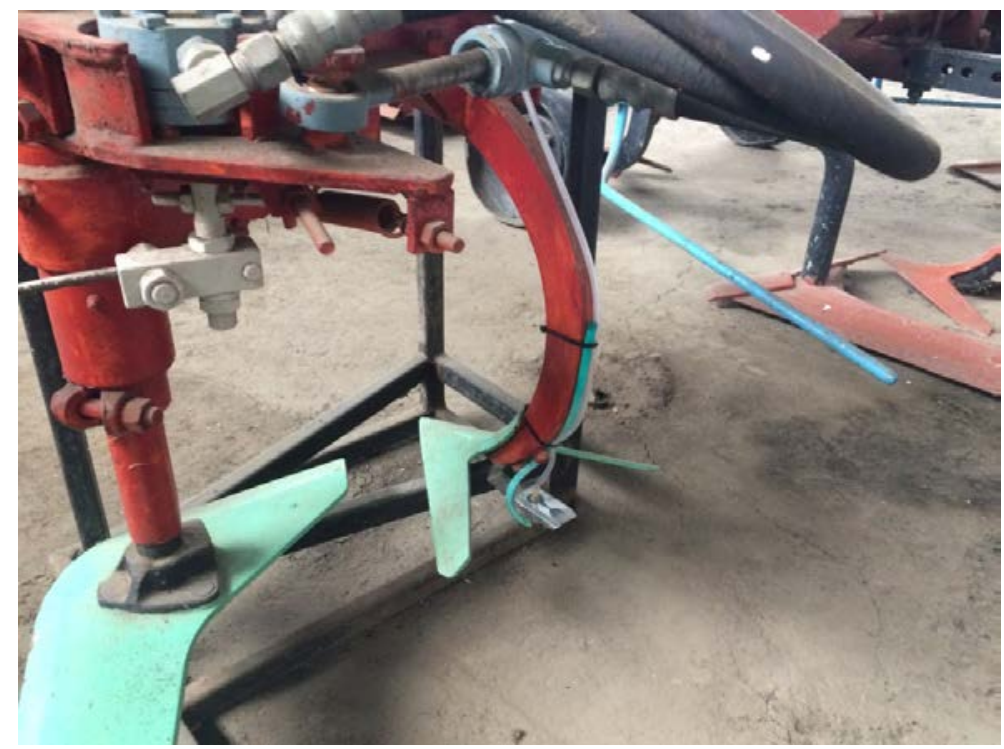

Fig. 2. Combined tillage tool on the basis of a garden cultivator.

We, when installed the dispensers behind stands of lancet legs of the cultivator, having a gripping width from 220 to $320 \mathrm{~mm}$, it is proposed to use a jet nozzle of a slit type. Above it was installed a feeding jet (tube) supplying the operation fluid into air flow to obtain a fine uniform spray over the width of the leg.

To determine the parameters of this air-droplet jet, we determined its velocity at a different distance from the jet nozzle, that is, from the leg's stand. We studied the spray of the open type, having a nozzle width of $8 \mathrm{~mm}$ and a thickness of $0.5 \mathrm{~mm}$. The rotator of flow formed by a flat strip with above parameters, created the air flow supplied by a compressor (probably a tractor) through the receiver and pressure regulator. The sprayer was located on a support where the bar was fixed on which the labels were applied from the nozzle of the sprayer consistently at a distance of $30 \mathrm{~cm}$ to $150 \mathrm{~cm}$ with a step of $30 \mathrm{~cm}$. The pressure in the pneumatic lines was installed sequentially 0,$15 ; 0,20 ; 0,25 ; 0,30 \mathrm{MPa}$. 


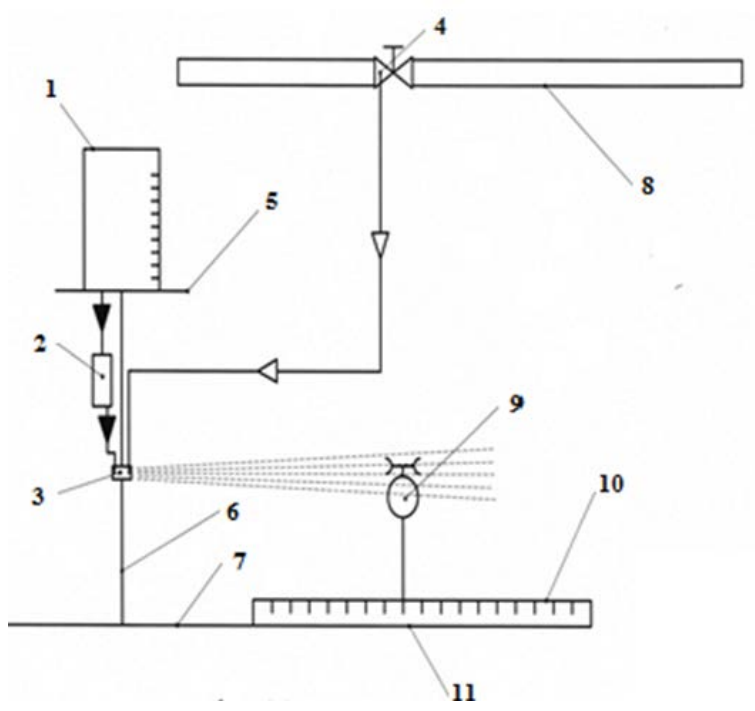

1 -measuring glass; 2 - leveling container; 3 - sprayer; 4 -valve; 5 -floor; 6 - bar; 7 - support; 8 - air collector; 9 -anemometer; 10 -measuring bar; 11 -retainer.

Fig. 3. Laboratory unit for air flow velocity measurement.

Along with the study of the velocity of the air flow created by the sprayer, the flow rate of operation fluid was determined depending on pressure in the pneumatic system and the diameter of the outlet of the sprayer.

For the study there was adopted the pneumatic slit sprayer of our department "PRiMA" of Kuban State Agrarian University. The air flow is created at the outlet of the slit nozzle having parameters $5 \times 0,8 \mathrm{~m}^{2}$. The air flow is supplied by pneumatic drives from the unit's compressor, the pressure from which is regulated by the adjuster and installed in limits from 0.1 MPa to 0.3 MPa in a step of $0.05 \mathrm{MPa}$. The air jet injects the operation fluid from the tube, into which it enters from the tank through a valve and a leveling container that stabilizes the head pressure of the operation fluid.

The study was carried out on a laboratory unit (Fig. 3) which has a support with mounting floor. The position of the unit relative to the horizontal initial surface is adjustable. It simulates the surface of the furrow's bottom, which is processed either by the ploughshare or by the cultivator's claw. The furrow's bottom should be processed with the appropriate operation fluid (fertilizers, chemical protection agents, biological products, microorganisms, etc.). Therefore, for researches there was adopted the position of the installation site corresponding to the height of the tillage tool $-40 \mathrm{~cm}$. Since the operation fluid flows out from the feeding tube of the sprayer, the diameters of the pipeline for the outflow of liquid were taken to be 3, 4, $5 \mathrm{~mm}$.

Diameter sizes were adopted as 3-5 mm in order to prevent clogging during operation and the possibility of using preparations with different density and viscosity as operation fluid.

But the study was conducted on water with density of $1000 \mathrm{l} / \mathrm{m}^{3}$ at temperature of 20 ${ }^{\circ} \mathrm{C}$ and in calm.

The sprayer was fixed to the stand of the cultivator's claw. There was switched on the compressor, installed the required planned pressure, and air flow was turned in airdrop jet in the nozzle exit injecting liquid from the tank. The sprayer was switched on for one minute and the flow rate of the operation fluid from the sprayer with a given diameter of the outlet at a given pressure was determined. 
Therefore, using a laboratory unit (Fig.3) we determine the capacity of the sprayer q, 1 / min depending on the difference in the height of the sprayer location on the tillage foot to the liquid level in the leveling container mounted on the frame of the unit $\mathrm{H}, \mathrm{m}$.

Table 1. Initial data on the sprayer

\begin{tabular}{|l|l|l|l|}
\hline $\begin{array}{l}\text { Parameters of the } \\
\text { nozzle, mm }\end{array}$ & $\begin{array}{l}\text { Diameter of initial outlet of } \\
\text { feeding tube, cm }\end{array}$ & $\begin{array}{l}\text { Operation air pressure, } \\
\text { MPa }\end{array}$ & $\begin{array}{l}\text { Position of leveling } \\
\text { tank }\end{array}$ \\
\hline $\begin{array}{l}\text { width } 18,0 \\
\text { thickness } 1,0\end{array}$ & 4 & 2,0 & $\begin{array}{l}+10,0,-10,-20,-30,-40,- \\
50\end{array}$ \\
\hline
\end{tabular}

The experiment was carried out in 3-fold repetition on the average values of the sprayer performance. According to the results of the experiment there was obtained the graph $q=f$ (H)

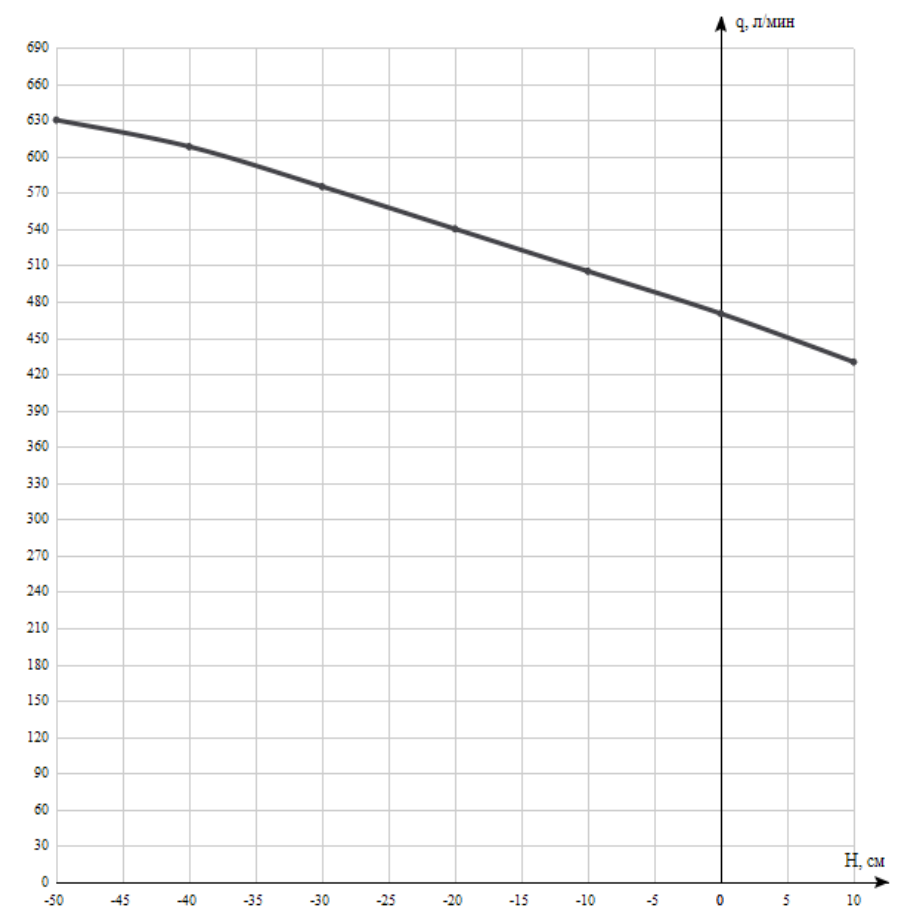

Fig. 4. Dependence of efficiency on fluid pressure in a hydraulic supply line.

The presented graph (Fig. 4) allows the simultaneous belt applying the corresponding operation fluid to a given depth behind the claw in soil which depends on fluid pressure and tasks of soil tillage, that is, shows the dependence on the design features of the unit.

In the result of studies there were substantiated the technological scheme of the unit for subsoil applying of protective-stimulating liquids and there was determined the influence of controllable factors (diameter feeding tube, air pressure in the pneumatic system and position of leveling capacity) on the size of the performance of the sprayer.

The speed of the air jet at the outlet of the nozzle is $40 \mathrm{~m} / \mathrm{s}$ and is reduced to $2 \mathrm{~m} / \mathrm{s}$ at a distance of $1.5 \mathrm{~m}$.

Increasing the diameter of the feeding tube at other constant factors leads to an increase in the productivity of the sprayer. 
The increase in pressure in the pneumatic line leads to a decrease in the flow rate of the operation fluid; so at a pressure of $1.5 \mathrm{MPa}$ the flow rate is $0.67 \mathrm{l} / \mathrm{min}$, and at $3 \mathrm{MPa}-0.56 \mathrm{l}$ / min for a sprayer with a feeding tube diameter of $5 \mathrm{~mm}$.

The maximum performance is achieved when the size of the jet rotator: throat- $6 \mathrm{~mm}$, nozzle outlet $18 \mathrm{~mm}$ and the angle of inclination of the feeding tube $30^{\circ}$

The proposed design of the unit for subsoil application of protective-stimulating liquids allows making them ultra low volume method with high processing quality of subsoil layers in the combined aggregate.

\section{References}

1. Maslov G.G., Ultra low volume sprayer /Maslov G.G., Borisova S.M., Nebavsky V.A., Medovnik A.N/ patent RUS 2132611.

2. Maslov G.G., Ejecting sprayer / Maslov G.G., Borisova S.M. /Mechanization and electrification of agriculture. 1994. № 7. P. 8.

3. Veletsky I.N., Lysov A.K., Lepekhin N.S. et al. Mechanization of plant protection: Reference book. M.:VO Agropromizdat, 1992. P.223.

4. Vinevsky E.I. Optimization of parameters of mechanization means by the method of multifactorial experiment planning / Vinevsky E.I., Popov G.V., Papusha S.K., Shidlovsky E.V., Ognyanik A.V., Venivskaya N.N., Bukatkin R.N./ Proceedings of AllRussian scientific-research institute of tobacco, makhorka and tobacco products. 2010. № 179. P. 300-312. 